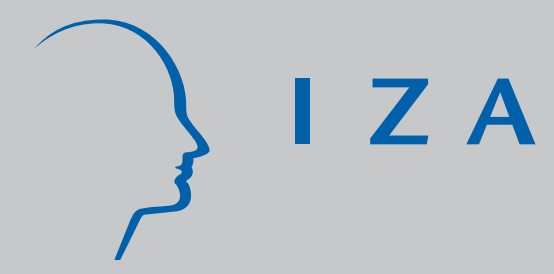

IZA DP No. 3723

How Working Time Reduction Affects

Employment and Earnings

Pedro S. Raposo

J an C. van Ours

September 2008 


\title{
How Working Time Reduction Affects Employment and Earnings
}

\author{
Pedro S. Raposo \\ Tilburg University \\ Jan C. van Ours \\ Tilburg University, CentER, \\ University of Melbourne, CEPR and IZA
}
Discussion Paper No. 3723
September 2008

\author{
IZA \\ P.O. Box 7240 \\ 53072 Bonn \\ Germany \\ Phone: +49-228-3894-0 \\ Fax: +49-228-3894-180 \\ E-mail: iza@iza.org
}

Any opinions expressed here are those of the author(s) and not those of IZA. Research published in this series may include views on policy, but the institute itself takes no institutional policy positions.

The Institute for the Study of Labor (IZA) in Bonn is a local and virtual international research center and a place of communication between science, politics and business. IZA is an independent nonprofit organization supported by Deutsche Post World Net. The center is associated with the University of Bonn and offers a stimulating research environment through its international network, workshops and conferences, data service, project support, research visits and doctoral program. IZA engages in (i) original and internationally competitive research in all fields of labor economics, (ii) development of policy concepts, and (iii) dissemination of research results and concepts to the interested public.

IZA Discussion Papers often represent preliminary work and are circulated to encourage discussion. Citation of such a paper should account for its provisional character. A revised version may be available directly from the author. 


\begin{abstract}
How Working Time Reduction Affects Employment and Earnings

December 1, 1996 Portugal introduced a new law on working hours which gradually reduced the standard workweek from 44 hours to 40 hours. We study how this mandatory working hours reduction affected employment and earnings of workers involved. We find for workers who were affected by the new law that working hours decreased, while hourly wages increased, keeping monthly earnings approximately constant. We also find that the working hours reduction did not lead to an increased job loss of workers directly affected. Finally, we find that workers who themselves were not directly affected were influenced by the working hours reduction indirectly. If they worked in a firm with many workers working more than 40 hours before the change in law was introduced.
\end{abstract}

JEL Classification: J22, J31, J63, J81

Keywords: workweek reduction, policy reform, employment dynamics, earnings

Corresponding author:

Jan C. van Ours

Department of Economics

Tilburg University

P.O. Box 90153

5000 LE Tilburg

The Netherlands

E-mail: vanours@uvt.nl

* Pedro S. Raposo gratefully acknowledges financial support by the Portuguese Foundation of Science and Technology, FCT [SFRH/BD/21906/2005]. 


\section{Introduction}

In the past decades, working hours have been reduced in many countries, often with the idea that a reduction of working time per worker would increase the number of employed workers. However, empirical studies find little if any support for positive employment effects of working hours reduction. For Germany, Hunt (1999) finds no positive employment effects of the gradual working time reduction that occurred in the 1980s and 1990s. Andrews et al. (2005) also find no evidence of positive employment effects of working hours reduction in Germany. For France, Crépon and Kramarz (2002) study the 1982 reduction of the workweek in France from 40 to 39 hours finding that it didn't create jobs but increased unemployment. Estevão and Sá (2008) study the further reduction of the workweek in France from 39 to 35 hours in 2000-2002. They find an increase in labor turnover but no effect on aggregate employment. Skuterud (2007) presents an analysis of the Canadian province of Quebec where the standard workweek was gradually reduced from 44 to 40 hours concluding that the policy failed to raise employment. Varejão (2005) investigates the effects of a 1996 working time reduction in Portugal finding that firms' reaction to the policy is affected by the presence of minimum wage earners and the use of overtime hours. In addition to the country studies Kapteyn et al. (2004) analyze cross-country differences in actual working hours which they interpret as work-sharing assuming that the reductions in actual working hours are driven by changes in standard hours. ${ }^{1}$ They find that work-sharing has a significant positive long-run effect on the wage rate and a positive but insignificant long-run effect on employment.

This paper investigates the effects of a working time reduction in Portugal. December 1, 1996 Portugal introduced a new law on working hours which gradually reduced the standard workweek from 44 hours to 40 hours. $^{2}$ Our contribution of this paper to the literature on working hours reduction is twofold. First, we present a more detailed analysis of potential effects. In order to assess the working hours re-

\footnotetext{
${ }^{1}$ Indeed, there is ample empirical evidence that actual hours follow standard hours. The analysis of Kapteyn et al. (2004) is based on data from 16 OECD countries over the time period 1960-2001.

${ }^{2}$ This working hours reduction is also studied by Varejão (2005). Our study is distinct from his study because we also take potential firm effects into account.
} 
duction policy we analyze its effects on normal hours of work, overtime hours, hourly wages, monthly earnings and the probability of job loss. Second, we use matched worker-firm data which allow us to study the effects of working hours reduction taking firm effects into account.

The set-up of this paper is as follows. In section 2 we discuss the nature of the working hours reduction in Portugal as well as our data. Section 3 presents the empirical analysis. Section 4 concludes.

\section{Working hours in Portugal}

\subsection{The working hours reduction}

In Portugal, the 1990s was a decade with unemployment rates that were low, about 3-4\%-points below the EU-15 average. Initially unemployment rates increased somewhat to a maximum of about $7 \%$ in the mid $1990 \mathrm{~s}$, to decrease to $4 \%$ in the late 1990s. Portugal has a highly regulated and centralized labor market, with minimum wages, strong employment protection, and collective bargaining widely applied (Cardoso (2006)).

December 1, 1996 a new law was introduced with the aim of gradually reducing the standard workweek from 44 to 40 hours. The law was not passed as a tool to create jobs and reduce unemployment but it was introduced because the newlyelected government wanted to speed up convergence of the traditionally long hours of work in Portugal to the European average (Varejão (2005)).

The new law implied a reduction of working hours in two steps. First, at $1^{\text {st }}$ December 1996 all workweeks above 42 hours should be reduced by 2 hours; workweeks below 42 hours but above 40 hours should meet the new standard of 40 hours per week. Second, at $1^{\text {st }}$ December 1997, all workweeks should meet the new standard of 40 hours.

Workers were still allowed to work overtime, with an overtime premium of $50 \%$ for the first hour and $75 \%$ for additional overtime hours. Of course, with the reduction of standard working hours, hours in the range 40-44 became more expensive so the 
firms had an incentive to reduce working hours. In order to compensate firms for the reduction in working hours the new law introduced some flexibility: the reduction was implemented taking into account that the normal workweek could be defined on a 4 months average. It was allowed to increase the maximum number of hours with 2 hours per day if the total did not exceed 10 hours per day and 50 hours per week.

\subsection{Our data}

In our analysis we use a longitudinal data set matching firms and workers in the Portuguese economy, called Quadros de Pessoal (QP - "Lists of Personnel"). The data are gathered annually by the Ministry of Employment, based on an inquiry that every establishment with wage-earners is legally obliged to fill in. Reported data cover all the personnel working for the establishment in a reference week. A worker identification code, based on a transformation of the social security number, enables tracking the worker over time. Every year QP gathers information for more than 200 thousand firms and 2 million workers (see Cardoso (2006) for more details). Until 1993 data were collected in March, from 1994 onwards data collection occurred in October. Because of the change in month of data collection we use data from 1994 onwards. $^{3}$

QP includes detailed information on the personal characteristics of each worker and firm. Our analysis focuses on workers who are full-time wage earners, i.e. workers working more than 35 hours per week. ${ }^{4}$ We dropped individuals with missing information on normal hours of work and monthly earnings. The period before the introduction of the working hours covers October 1994 to October 1996. According to the way the law was implemented, the impact of the law is expected to take more

\footnotetext{
${ }^{3}$ We exploit a $10 \%$ random sample using the Stata sampling procedure "sample2". This procedure allows the creation of a random sample by clusters of observations. Once an individual is randomly chosen all observations of this individual are sampled. Thus a sample with the original panel characteristics of the population is created.

${ }^{4}$ The main reason is that workers working less than 35 hours may have a different attachment to the labor market.
} 
than a year to completely take effect. We consider the situation in October 1997 to represent the short term effects of the December 1996 change in law, while the situation in October 1998 is assumed to represent the long term effects.

Our main variables are defined as follows. Normal hours are defined as the hours worked during a normal week. This measure excludes irregular or unusual overtime, work for premium pay, regular pay, or no pay at all, and by unusual absence or rest. Overtime hours are defined as the time worked in addition to the hours worked during normal periods of work, having a higher hourly wage rate than the normal rate. ${ }^{5}$ Monthly earnings are the monthly payments associated with the normal hours of work. We use the national consumer price index to transform nominal earnings into real ones. The hourly wage is computed as the ratio of monthly earnings and normal hours of work. The worker is considered to lose his job in 2 situations. First, if he comes in our sample twice in the same year, in which case we consider he changed job, with or without an intermediate spell of unemployment. Second, if he disappears from our sample for at least one year, in which case we assume that the worker became unemployed or left the labor force.

\section{Empirical analysis}

\subsection{Stylized facts}

Table 1 shows that in the period October 1994-1996 on average 22\% of the Portuguese workers had a normal workweek between 40 and 42 hours, while $30 \%$ had a workweek of more than 42 hours. So, half of the Portuguese workers was affected by the reduction in working hours. By October 1997 the percentage of workers working more than 40 hours decreased to 38 and by October 1998 only $9 \%$ of the workers worked more than 40 hours. ${ }^{6}$ The histograms in figures 1 and 2 show the

\footnotetext{
${ }^{5} \mathrm{QP}$ collects information on both normal and overtime hours collected in the reference month and a posteriori we transformed them into the week reference.

${ }^{6}$ Note that formally in October 1998 all workers had to have a workweek of at most 40 hours; The explanation of us finding that $9 \%$ of workers is working more than 40 hours per week is twofold. First, the transformation of monthly to weekly hours information may introduce some
} 
distribution of usual and total workers hours before and after the introduction of the new working hours law. Clearly, the fraction of workers working more than 40 hours clearly decreased and almost disappeared after 1997.

Table 1 shows that the number of individuals working part-time is not large and this number doesn't change much over time. As was to be expected working hours reduced substantially, with the category 35-40 increasing with 17\%-points between October 1996 and 1997, and further increasing with 26\%-points between October 1997 and 1998. The category 40-42 hours initially didn't change much, while the category of more than 42 hours almost completely vanished in two steps of about equal size.

The law concerning the reduction of the workweek was introduced sudden and unexpected. Thus, the impact of the law can be analyzed as if it was a "natural experiment". In our analysis we assume that the workers working 35-40 hours per week in October 1996 are the control group, i.e. these workers are not directly affected by the reduction of working hours. The workers working more than 40 hours are affected by the policy change. Because the working hours reduction was implemented in two steps that affected the hours categories 40-42 and above 42 differently we distinguish two treatment groups accordingly. Table 2 shows how workers in various hours categories changed working hours or lost their job; the upper part presents the changes in usual hours while the lower part presents the changes in total working hours. Panel $a$ presents the changes before the introduction of the working hours law. As shown many workers do not change their hours category, but there is also a large fraction of individuals who loose their job (22 to 29\%), specially in the categories over 40 hours. Panel $b$ shows the transition by working hours categories from October 1996 to October 1997. This panel shows what happens to workers in the control group and both treatment groups. Panel $c$ shows the differences between the changes presented in panels $a$ and $b$. The control group is affected only by the economic cycle, whereas both treatment groups are affected by the cycle and by the workings hours law. If we take the difference of the differences

measurement error. Second, as explained before under the new law the normal workweek was defined on a 4 months average. Therefore, for the reference week normal hours could exceed 40. 
between both treatment groups and the control group we get a first impression of the effects of the change in mandatory working hours. These differences in differences are shown in panel $d$. Clearly the policy change did not have a large effect on the probability of job loss, but there were clear and sizeable effects on the distributions of working hours.

\subsection{Parameter estimates}

As indicated before, we analyze the impact of the reduction of the workweek as if the policy change resembles a natural experiment. The treatment groups consist of all individuals who worked more than 40 hours in October 1996, either 40-42 or 42+. The control group consists of workers who worked 35-40 hours in October 1996. To establish the effects of the working week reduction we estimate the following equations using QP data from October 1994 - October 1998:

$$
\Delta y_{i t}=\beta x_{i t}+\left(\delta_{1} h_{4042, i}+\delta_{2} h_{42 p, i}\right) d_{96, i t}+\left(\delta_{3} h_{4042, i}+\delta_{4} h_{42 p, i}\right) d_{97, i t}+\epsilon_{i t}
$$

where $\Delta y$, the dependent variable, represents changes in normal hours, overtime hours, hourly wages, monthly wages and employment status for individual $i$ in the period from October in year $t$ to October in year $t+1$. Furthermore, $x$ represents a vector of personal characteristics. Included in $x$ are $d_{96}$ and $d_{97}$, dummy variables indicating calendar years and $h_{4042}$ and $h_{42 p}$ dummy variables representing working hours categories, 40-42 hours per week and more than 42 hours per week respectively. Both categories are defined on the basis of the situation in October 1996, just before the introduction of the working time reduction. Finally, $\beta$ is a vector of parameters, the $\delta$ 's are also parameters while $\epsilon$ is an error term.

Assuming that the general calendar time effects are represented by the calendar year dummies and assuming that the time-invariant work hours-specific effects are represented by the working hours categories, the interaction terms represent the treatment effects. Our main interest concerns the short-run treatment effects represented by $\delta_{1}$ and $\delta_{2}$, and the long-run effects represented by $\delta_{3}$ and $\delta_{4}$. The relevant parameter estimates are presented in Table 3. 
As expected normal hours go down substantially. Overtime hours increase in the first year, but in the second year they are approximately constant. Apparently, the initial reduction of normal working hours is partly compensated by an increase in overtime hours although this effect is small. Hourly wages for workers affected increase, leaving monthly earnings approximately constant. Somewhat surprisingly the affected workers in the category 40-42 hours have a lower probability to lose their job than non-affected workers. This may be explained by the flexibility that firms could use on this group of workers.

So far, we only considered individual direct effects of the policy change ignoring firm effects. However, it may be that the effects are influenced by the firm share of workers that worked more than 40 hours per week. Firms that had many workers who were potentially affected may have responded different from firms that only had a few affected workers. To investigate this possibility we add to equation (1) a number of interaction terms: ${ }^{7}$

$$
\begin{aligned}
& \Delta y_{i t}=\beta x_{i t}+\left(\zeta_{1} \cdot n+\left(\delta_{1}+\omega_{1} \cdot n\right) h_{4042, i}+\left(\delta_{2}+\omega_{2} \cdot n\right) h_{42 p, i}\right) d_{96, i t} \\
& +\left(\zeta_{2} \cdot n+\left(\delta_{3}+\omega_{3} \cdot n\right) h_{4042, i}+\left(\delta_{4}+\omega_{4} \cdot n\right) h_{42 p, i}\right) d_{97, i t}+\epsilon_{i t}
\end{aligned}
$$

where $n$ represents the share of workers in the firm in worker $i$ that worked more than 40 hours in October 1996. To the extent that the $\omega$ 's differ from zero the composition of the workforce affects the treatment effect. The $\zeta$ parameters represent the effects of the working hours reduction on workers who themselves were not directly affected. These effects originate from spillover effects because the position of a worker in a firm with many affected workers is different from the position of a worker in a firm with few affected workers.

Looking first in Table 4 to the effect on the affected workers we see that the firm's share of affected workers does not affect the number of normal hours affected workers do in October 96-97 but in October 97-98 it decreases significantly the number of hours the $42+$ hours group does. The firm's share of affected workers decreases the hourly wage of affected workers in October 96-97 but it increases it in October

\footnotetext{
${ }^{7}$ And, we also added $n_{i}$ to the equation to make sure that the $\omega$-parameters represent the treatment effects.
} 
97-98. Affected workers have a lower probability of loosing their job if the firm has a large share of affected workers both in October 96-97 and October 97-98.

Other important parameters of interest concern the $\zeta$ 's representing the short run and long run effects of the firm's share of affected workers on workers not directly affected by the working hours reduction. As shown, those non-directly affected workers were nevertheless affected significantly. Non-affected workers increase the number of hours they work if the proportion of affected workers in the firm is large. Non-affected workers have a bigger probability of loosing their job if the firm has a large share of affected workers.

As shown in Table $4 \omega_{1}$ and $\omega_{2}$ are often insignificantly different from zero indicating that in the short run the composition of the workforce is not very important. However, since the other $\omega$-parameters often differ significantly from zero, in the long-run the treatment effect is influenced by the workforce composition.

Table 5 gives an idea of the size of the firm effects by presenting treatment effects calculated on the basis of the parameter estimates of Table 4. From these calculations we draw two conclusions. First, the treatment effects are bigger - in absolute terms - for workers who worked more than 42 hours per week, with one exception, the employment effect. Workers in the category 40-42 hours are less likely to lose their job than workers working fewer or more hours. Our second conclusion concerns the firm effects. Most of the treatment effects do not depend on the share of workers working 40 hours or more. Apparently, the firm effects are significant but quantitatively not very important. The only exception concerns the long term effects on employment. Somewhat surprisingly, the employment effects are more favorable the higher the share of workers working more than 40 hours. Our interpretation of this phenomenon is that there are negative spillover effects affecting the employment of workers that worked less than 40 hours per week.

\section{Conclusions}

The reduction of working hours in Portugal was mandated by law in 1996. Its objectives was to reduce the workweek from 44 to 40 hours and to increase flexibility. The 
change in law was not intended as an instrument to increase employment through work-sharing. The reduction of working hours from 44 to 40 directly affected about half of all workers in Portugal since they were working more than 40 hours per week prior to the introduction of the law. The law was introduced in a sudden and unexpected way, which allowed us to establish its effects as if it was a "natural" experiment.

Our main findings are as follows. Initially, the reduction of working hours was compensated by the use of overtime. Hourly wages of the affected workers increased, reducing their monthly wage only slightly. Workers in the category 40-42 hours were less likely to lose their job. We also find that workers who themselves are not directly affected by the working hours reduction experience effects if they are in a firm with many workers that were affected. 


\section{References}

Andrews, M., Schank, T., and Simmons, R. (2005). Does worksharing work? some empirical evidence from the IAB-establishment panel. Scottish Journal of Political Economy, 52:141-176.

Cardoso, A. (2006). Wage mobility: Do institutions make a difference? a replication study comparing Portugal and the UK. Labour economics, 13(3):387-404.

Crépon, B. and Kramarz, F. (2002). Employed 40 hours or not-employed 39: Lessons from the 1982 workweek reduction in France. Journal of Political Economy, 110(6):1355-1389.

Estevão, M. and Sá, F. (2008). The 35 hour workweek in France: straightjacket or welfare improvement? Economic Policy, 55:417-463.

Hunt, J. (1999). Has work-sharing worked in Germany? The Quarterly Journal of Economics, 114:117-148.

Kapteyn, A., Kalwij, A., and Zaidi, A. (2004). The myth of work-sharing. Labour Economics, 11:293-313.

Skuterud, M. (2007). Identifying the potential of work-sharing as a job-creation strategy. Journal of Labor Economics, 25(2):265-287.

Varejão, J. (2005). Work-sharing revisited - lessons from a natural experiment. Mimeo, Universidade do Porto. 
Table 1: Proportion of workers in each hour category; normal working hours

\begin{tabular}{|c|c|c|c|c|c|}
\hline & \multicolumn{3}{|c|}{ October } & \multirow{2}{*}{$\begin{array}{c}\Delta \\
1994 / 6-97\end{array}$} & \multirow{2}{*}{$\begin{array}{c}\Delta \\
1997-98\end{array}$} \\
\hline & 1994-1996 & 1997 & 1998 & & \\
\hline$<35$ & 11 & 8 & 11 & -3 & 3 \\
\hline $35-40$ & 37 & 54 & 80 & 17 & 26 \\
\hline $40-42$ & 22 & 23 & 8 & 1 & -15 \\
\hline$>42$ & 30 & 15 & 1 & -15 & -14 \\
\hline Total & 100 & 100 & 100 & 0 & 0 \\
\hline
\end{tabular}


Table 2: Transition rates given usual hour category in $\mathbf{t}$

\begin{tabular}{lccccccc} 
Usual hours & \multicolumn{7}{c}{$t+1$} \\
\multicolumn{1}{c}{$t$} & & Loose job & $<35$ & $35-40$ & $41-42$ & $>42$ & Total \\
\hline a. 1994-1995 & $35-40$ & 22 & 4 & 61 & 12 & 1 & 100 \\
& $41-42$ & 25 & 2 & 11 & 59 & 3 & 100 \\
& $>42$ & 29 & 3 & 10 & 25 & 33 & 100 \\
\hline b. 1996 & $35-40$ & 21 & 3 & 70 & 6 & 0 & 100 \\
& $41-42$ & 24 & 2 & 30 & 43 & 1 & 100 \\
& $>42$ & 25 & 2 & 14 & 45 & 14 & 100 \\
\hline c. $\triangle$ & $35-40$ & -1 & -1 & 9 & -6 & -1 & 0 \\
& $41-42$ & -1 & 0 & 19 & -16 & -2 & 0 \\
& $>42$ & -4 & -1 & 4 & 20 & -19 & 0 \\
\hline d. $\triangle \triangle$ & $41-42$ & 0 & 1 & 10 & -10 & -1 & 0 \\
& $>42$ & -3 & 0 & -5 & 26 & -18 & 0 \\
\hline
\end{tabular}

Usual plus overtime hours

\begin{tabular}{lccccccc} 
& \multicolumn{7}{c}{$t+1$} \\
\multicolumn{1}{c}{$t$} & & Loose job & $<35$ & $35-40$ & $41-42$ & $>42$ & Total \\
\hline a. 1994-1995 & $35-40$ & 23 & 4 & 58 & 13 & 2 & 100 \\
& $41-42$ & 25 & 2 & 11 & 56 & 5 & 100 \\
& $>42$ & 21 & 2 & 10 & 25 & 42 & 100 \\
\hline b. 1996 & $35-40$ & 21 & 2 & 68 & 8 & 1 & 100 \\
& $41-42$ & 24 & 2 & 29 & 42 & 3 & 100 \\
& $>42$ & 22 & 2 & 14 & 36 & 26 & 100 \\
\hline c. $\triangle$ & $35-40$ & -2 & -2 & 10 & -5 & -1 & 0 \\
& $41-42$ & -1 & 0 & 18 & -14 & -3 & 0 \\
& $>42$ & 0 & -4 & 14 & -9 & -1 & 0 \\
\hline d. $\triangle \triangle$ & $41-42$ & 1 & 2 & 8 & -9 & -2 & 0 \\
& $>42$ & 2 & -2 & 4 & -4 & 0 & 0 \\
\hline
\end{tabular}

Source: QP 
Table 3: Parameter estimates - baseline model

\begin{tabular}{lcccccc}
\hline & $\begin{array}{c}\text { Normal } \\
\text { hours }\end{array}$ & $\begin{array}{c}\text { Overtime } \\
\text { hours }\end{array}$ & $\begin{array}{c}\text { Hourly } \\
\text { wage }\end{array}$ & $\begin{array}{c}\text { Monthly } \\
\text { earnings }\end{array}$ & $\begin{array}{c}\text { Non } \\
\text { employment }\end{array}$ \\
\hline Short run effects & & & & & \\
\hline $40-42$ hours & $\left(\delta_{1}\right)$ & $-1.52(35.8)^{* *}$ & $0.06(2.6)^{* *}$ & $3.65(13.5)^{* *}$ & $-0.47(1.6)$ & $-4.94(13.6)^{* *}$ \\
$42+$ hours & $\left(\delta_{2}\right)$ & $-3.58(95.2)^{* *}$ & $0.08(4.8)^{* *}$ & $8.26(34.9)^{* *}$ & $-0.57(2.2)^{* *}$ & $0.01(0.0)$ \\
\hline Long run effects & & & & & \\
\hline $40-42$ hours & $\left(\delta_{3}\right)$ & $-0.88(18.2)^{* *}$ & $0.05(2.2)^{* *}$ & $2.92(11.4)^{* *}$ & $0.49(1.7)^{*}$ & $-5.73(16.4)^{* *}$ \\
$42+$ hours & $\left(\delta_{4}\right)$ & $-2.39(55.3)^{* *}$ & $0.02(1.4)$ & $5.88(25.9)^{* *}$ & $0.05(0.2)$ & $-0.01(0.3)$ \\
\hline $\bar{R}^{2}$ & 0.085 & 0.0001 & 0.011 & 0.013 & 0.040 \\
\hline
\end{tabular}

Note: Ordinary least squares; first four columns based on 415,863 observations, the fifth column based on 536,997 observations; parameter estimates of control variables are not represented; control variables include calendar year dummies for 1996 and 1997, working hours dummies for categories 40-42 hours and more than 42 hours, industry (10 categories), region ( 7 categories), education ( 8 categories), wage (5 categories)(not included in the wage and earnings regressions), size of firm (4 categories) and tenure. The population includes all full-time workers in the private sector working between 35 and 50 hours. absolute $t$-statistics based on robust standard errors in parentheses, a $* * / *$ indicates that the coefficient is different from zero at a $5 \% / 10 \%$ level of significance. 
Table 4: Additional parameter estimates

\begin{tabular}{lccccc}
\hline \multicolumn{1}{c}{$\begin{array}{c}\text { Normal } \\
\text { hours }\end{array}$} & $\begin{array}{c}\text { Overtime } \\
\text { hours }\end{array}$ & $\begin{array}{c}\text { Hourly } \\
\text { wage }\end{array}$ & $\begin{array}{c}\text { Monthly } \\
\text { earnings }\end{array}$ & $\begin{array}{c}\text { Non } \\
\text { employment }\end{array}$ \\
\hline Short run effects & $-2.49(-20.3)^{* *}$ & $0.02(0.2)$ & $6.04(7.1)^{* *}$ & $-1.37(-1.5)$ & $-3.63(-3.4)^{* *}$ \\
\hline $40-42$ hours & $-0.02(-0.1)$ & $-0.01(-0.1)$ & $-2.39(-2.1)^{* *}$ & $-1.49(-1.2)$ & $-3.34(-2.3)^{* *}$ \\
$\delta_{1}$ & & & & \\
$\omega_{1}$ & $-4.67(-35.9)^{* *}$ & $0.00(0.1)$ & $9.96(13.2)^{* *}$ & $-1.59(-1.9)^{*}$ & $0.32(0.3)$ \\
$42+$ hours & $-0.21(-1.3)$ & $0.03(0.4)$ & $-1.33(-1.3)$ & $-1.41(-1.3)$ & $-1.97(-1.5)$ \\
$\delta_{2}$ & $1.89(19.9)^{* *}$ & $0.09(2.4)^{* *}$ & $-1.44(-2.3)^{* *}$ & $3.61(5.3)^{* *}$ & $1.83(2.3)^{* *}$ \\
$\omega_{2}$ & & & & \\
$35-40$ hours & & & & & \\
$\zeta_{1}$ & $0.04(0.3)$ & $-0.11(-1.8)^{*}$ & $0.77(1.1)$ & $0.83(1.0)$ & $-1.27(-1.3)$ \\
\hline Long run effects & $-2.42(-12.7)^{* *}$ & $0.21(2.3)^{* *}$ & $3.22(3.3)^{* *}$ & $-3.65(-3.2)^{* *}$ & $-10.18(-7.3)^{* *}$ \\
\hline $40-42$ hours & & & & & \\
$\delta_{3}$ & $-1.93(-14.2)^{* *}$ & $-0.02(-0.5)$ & $5.39(8.1)^{* *}$ & $0.65(0.8)$ & $5.24(5.9)^{* *}$ \\
$\omega_{3}$ & $-1.73(-9.3)^{* *}$ & $0.04(0.6)$ & $0.75(0.8)$ & $-4.02(-3.7)^{* *}$ & $-11.09(-8.9)^{* *}$ \\
$42+$ hours & & & & & \\
$\delta_{4}$ & $1.49(15.1)^{* *}$ & $0.03(0.8)$ & $-0.14(-0.3)$ & $4.30(6.9)^{* *}$ & $5.11(6.9)^{* *}$ \\
$\omega_{4}$ & 0.089 & 0.0002 & 0.014 & 0.003 & 0.040 \\
$35-40$ hours & $166.44(0.0)^{* *}$ & $2.07(0.0)^{* *}$ & $20.43(0.0)^{* *}$ & $9.06(0.0)^{* *}$ & $18.19(0.0)^{* *}$ \\
$\zeta_{2}$ & & &
\end{tabular}

Note: Ordinary least squares; first four columns based on 415,863 observations, the fifth column based on 536,997 observations; parameter estimates of control variables are not represented; control variables include calendar year dummies for $1996\left(d_{96, i t}\right)$ and 1997 $\left(d_{97, i t}\right)$, working hours dummies for categories 40-42 hours and more than 42 hours, the firm share of workers affected by the policy change $\left(n_{i}\right)$, industry (10 categories), region ( 7 categories), education ( 8 categories), wage ( 5 categories)(not included in the wage and earnings regressions), size of firm (4 categories) and tenure. The population includes all full-time workers in the private sector working between 35 and 50 hours. absolute $t$-statistics based on robust standard errors in parentheses; the $F$-statistic concerns a comparison of the estimation results in this table and the previous table (Table 3); a **/* indicates that the coefficient is different from zero at a $5 \% / 10 \%$ level of significance. 
Table 5: Simulated effects of working time reduction

\begin{tabular}{lcccccc}
\hline Weekly working hours & \multicolumn{2}{c}{$35-40$} & \multicolumn{2}{c}{$40-42$} & \multicolumn{2}{c}{$>42$} \\
\% of workers affected & 25 & 50 & 25 & 50 & 25 & 50 \\
& $(1)$ & $(2)$ & $(3)$ & $(4)$ & $(5)$ & $(6)$ \\
\hline Short run effects & & & & & & \\
Normal hours & 0.5 & 1.0 & -2.5 & -2.5 & -4.7 & -4.8 \\
Overtime hours & 0.0 & 0.0 & 0.0 & 0.0 & 0.0 & 0.0 \\
Hourly wage (\%) & -0.6 & -1.2 & 5.4 & 4.8 & 9.6 & 9.3 \\
Monthly earnings (\%) & 0.9 & 1.8 & -1.7 & -2.1 & -1.9 & -2.3 \\
Job loss (\%) & 0.5 & 0.9 & -4.5 & -5.3 & -0.2 & -0.7 \\
\hline Long run effects & & & & & & \\
Normal hours & 0.4 & 0.7 & -0.6 & -1.2 & -2.4 & -2.8 \\
Overtime hours & 0.0 & 0.0 & -0.1 & -0.0 & -0.0 & 0.0 \\
Hourly wage (\%) & -0.0 & -0.1 & 1.6 & 2.4 & 5.6 & 5.8 \\
Monthly earnings (\%) & 1.1 & 2.2 & -0.1 & -1.0 & -0.4 & -1.4 \\
Job loss (\%) & 1.3 & 2.6 & -3.8 & -6.4 & 2.5 & -0.3 \\
\hline
\end{tabular}

Note: The percentage of workers affected concerns the workers that worked more than 40 hours per week in October 1996; the calculations are based on the parameter estimates of the lower part of Table 4 
Figure 1: Usual working hours before and after introduction of the working hours law; October data

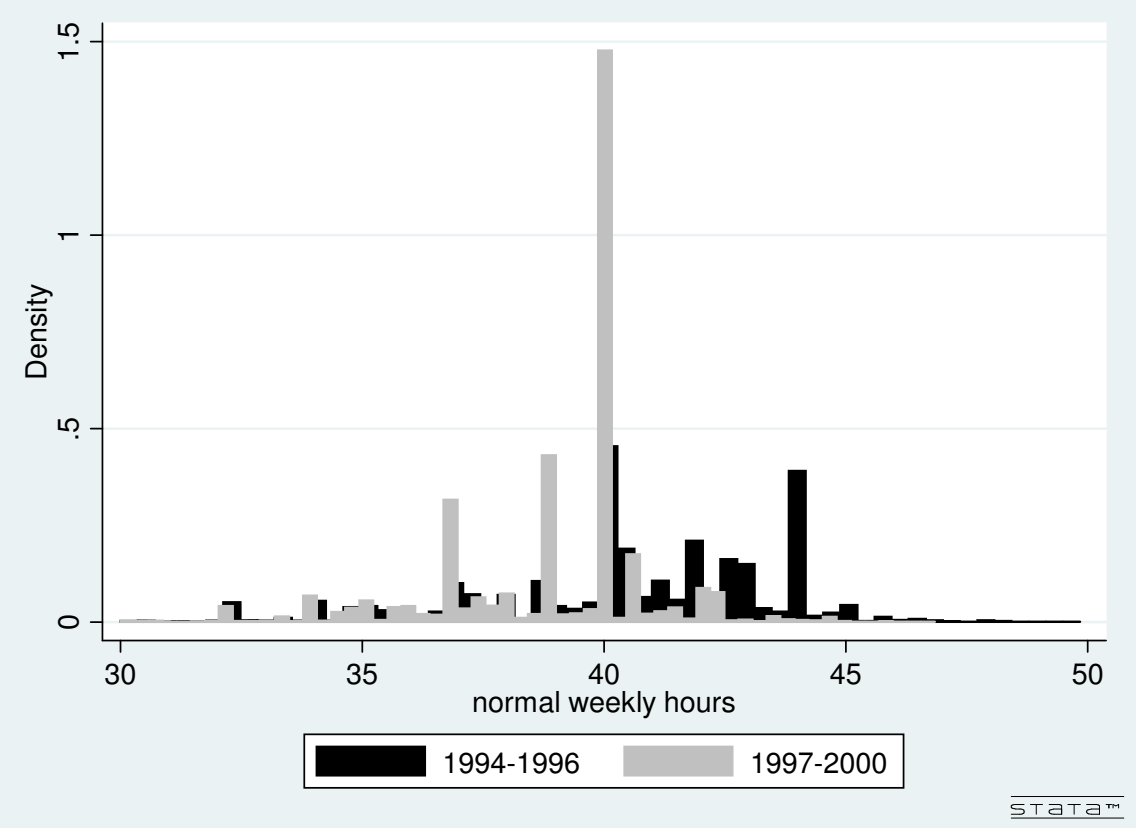


Figure 2: Total working hours (usual + overtime) before and after introduction of the working hours law; October data

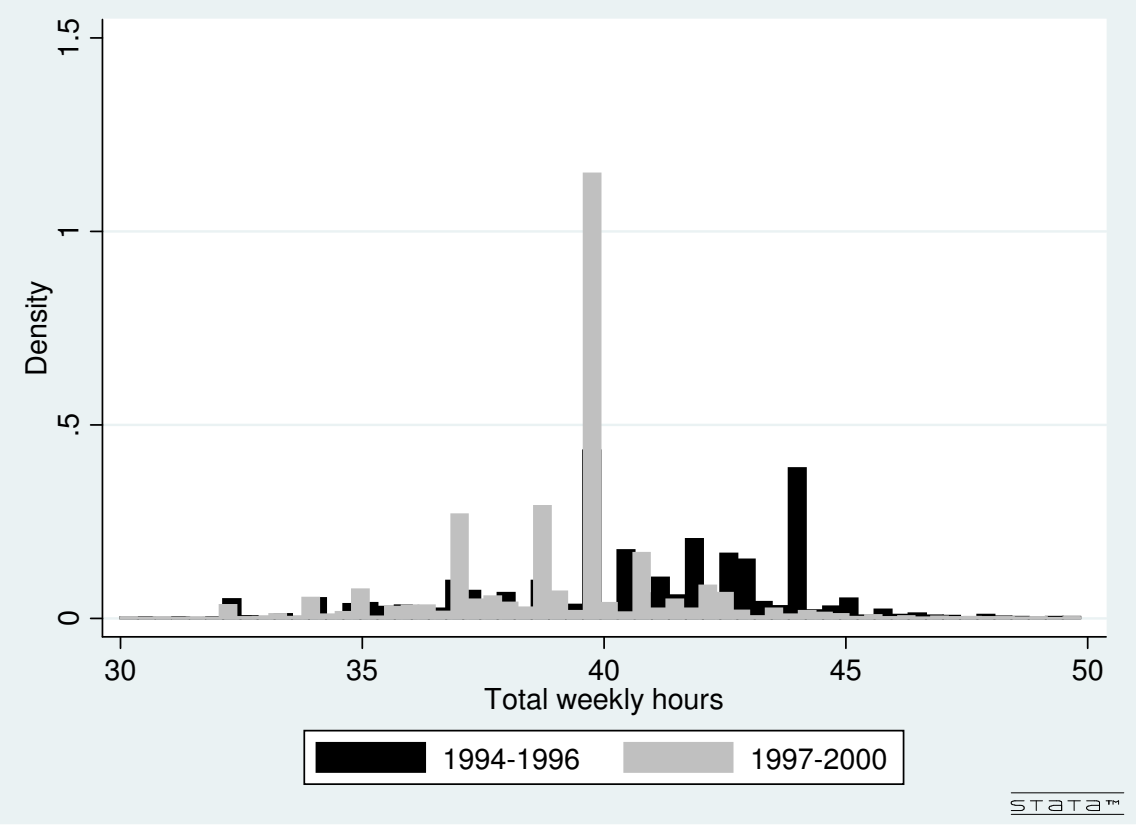

